\title{
Dapsone Attenuates the Severity of Gastric Erosion Induced by Ethanol; Stress; and Indomethacin in Rats: A Pharmacological Approach
}

\section{Mohammad Sheibani}

Tehran University of Medical Sciences School of Medicine

\section{Sadaf Nezamoleslami}

Tehran University of Medical Sciences School of Medicine

Nastaran Rahimi

Tehran University of Medical Sciences

\section{Ata Abbasi}

Urmia University of Medical Sciences

ahmad reza dehpour ( $\nabla$ dehpour@yahoo.com )

Tehran University of Medical Sciences https://orcid.org/0000-0002-8001-5565

\section{Research}

Keywords: Gastric erosion, Inflammation, Dapsone, Rat, Ethanol, Stress, Indomethacin

Posted Date: September 14th, 2020

DOl: https://doi.org/10.21203/rs.3.rs-72758/v1

License: (9) This work is licensed under a Creative Commons Attribution 4.0 International License. Read Full License 


\section{Abstract}

Background: Dapsone, as an antimicrobial compound, has shown strong anti-inflammatory properties in clinical and experimental studies. Inflammation in stomach mocusa produce gastric erosion. Several factors contribute to the development of gastric erosions, including corticosteroids and nonsteroidal antiinflammatory drugs (NSAIDs), alcohol, and stress. The aim of this study, therefore, was to evaluate the effects of dapsone against gastric erosions-induced by alcohol, stress, or indomethacin in rat.

Methods: Gastric damage was induced in male rats in different three experimental models including ethanol ( $5 \mathrm{ml} / \mathrm{kg}$, p.o.)-, water-immersion stress-, and indomethacin $(30 \mathrm{mg} / \mathrm{kg}$, p.o.)- induced gastric injury. Macroscopic lesion scores (the J-score), inflammatory cytokines levels, NF-kB protein expression, MPO activity, and histopathological evaluation were assessed.

Results: Induction of erosion in gastric mocusal led to a significant increase in J-score as an index of macroscopic parameter, tumor necrosis factor-alpha (TNF-a), interleukin-1beta (IL-1 $\beta$ ) as biochemical markers, NF-KB and myeloperoxidase (a marker of neutrophil activation, as well microscopic deterioration. Dapsone reduced the tissue injuries and erosion area, serum levels of inflammatory cytokines, the expression of NF-kB and tissue concentration of myeloperoxidase (a marker of neutrophil activation) in all three experimental groups. Furthermore, the histopathological studies revealed the reduction of damages in dapsone treated animals.

Conclusions: To conclude, dapsone exhibits significant gastro-protective effects against the development of experimental gastric erosions in rats which seems to be related to its anti-inflammatory properties.

\section{Introduction}

Peptic ulcers is a major disorder in the digestive tract which is associated with high mortality and morbidity $[1,2]$. The major causes of gastric epithelial damage are H.pylori infection, stress, ethanol as well as medications such as corticosteroids and NSAIDs [3-5]. Different mechanisms contribute to the development of gastric erosions. For example inhibition of cyclooxygenase (COX), blockade of the production of prostaglandins, reduce the protective effects of prostaglandins on gastric mucosa, which causes submucosal erosion and gastrointestinal ulcer by NSAIDs [6, 7]. Prostaglandins are also involved in protective and therapeutic effects of gastrointestinal hormones in the digestive system [8-10]. The essential role in the protection and healing of the mucous membrane plays the maintenance of adequate blood flow in the gut [11]. Mucosal ischemia following decreased gastric mucosal blood flow also plays a role in pathogenesis of gastric mucosal damage induced by stress and ethanol [12,13]; as well reduction of gastric mucosal blood and subsequent ischemia-reperfusion by stress [14]. In addition, inflammatory processes and oxidative stress plays a role in these processes. Disruption of gastric mucosal defense mechanisms such as mucus and bicarbonate secretion, anti-inflammatory and antioxidant agents are further factors leading to the development of peptic ulcers [15-18]. 
Dapsone is an antimicrobial compound of synthetic sulfone family used in the treatment of numerous systemic and dermatologic disorders. Similar to the sulphonamide drugs dapsone acts by competing with para-aminobenzoic acid for the active site of the enzyme dihydropteroate synthetase and via inhibiting the synthesis

of dihydrofolic acid [19]. Dapsone has anti-inflammatory properties equivalent to the NSAIDs [20, 21]. It appears that dapsone can reduce the level of inflammatory cytokines, adhesion molecules, lymphocyte activity and leukotrienes. Dapsone inhibits chemoattractant-induced signal transduction followed by suppression of neutrophil adherence in skin dermatitis [22]. Moreover, dapsone can inhibit the synthesis of both prostaglandins and leukotrienes by macrophages [23]. Studies have also shown that dapsone has antioxidant properties and is able to reduce reactive oxygen species (ROS) formation [24]. Besides, dapsone can reduce the amount myeloperoxidase enzymes leading to inhibition of $\mathrm{HOCl}$ formation [25].

Given anti-inflammatory effect of dapsone, this study was designed to investigate the protective effects of dapsone in gastric erosions induced from ethanol, water-immersion stress, and NSAIDs in rats.

\section{Material And Methods}

\section{Animal preparations}

Male Wistar rats weighing 250-300 g were used in this study. They were maintained under normal conditions such as free access to food and water, $23 \pm 2^{\circ} \mathrm{C}$ room temperature, $12 \mathrm{~h}$ light and $12 \mathrm{~h}$ dark cycles and standard humidity. One day before experiment, all rats were deprived of food but had free access to water. All experiments were carried out according to the National Institutes of Health guide for the care and use of laboratory animals (NIH Publications No. 8023, revised 1978). The Ethical Committee of Tehran University of Medical Sciences, approved all experiment details and animal study. (IR.TUMS.VCR.REC.1398.225).

\section{Drugs}

Dapsone powder was a gift from Gilaranco Co, Tehran, Iran and dissolved in normal saline. Absolute ethanol (Merck, Germany) was diluted 1:1 (vol/ vol) in water. Indomethacin (Sigma-Aldrich, United States) was suspended in $1 \%$ carboxymethyl cellulose solution.

\section{Experimental procedures}

120 male Wistar rats were used in this study and were randomly divided into 3 experimental models:

Model 1: Ethanol-induced gastric damage: Ethanol-induced erosion was produced by administration of 5 $\mathrm{ml} / \mathrm{kg}$ of ethanol $(1: 1 \mathrm{v} / \mathrm{v})$ via oral gavage [26]. 
Model 2: Water immersion stress model: Stress erosion were induced by immersing restrained rats in cold water $\left(23^{\circ} \mathrm{C}\right)$ up to the level of animal necks for 3 and a half an hours as described [27].

Model 3: Indomethacin-induced gastric damage; Indomethacin-induced erosion was produced by oral administration of indomethacin at a single dose of $30 \mathrm{mg} / \mathrm{kg}$ by gavage [28].

Each of three experimental models were divided into 5 groups of eight rats, which included 1 . Normal group (rats without any intervention), 2. Control (peptic erosion-induced group + vehicle), 3. Gastric erosion + pretreated dapsone $1 \mathrm{mg} / \mathrm{kg}, 4$. Gastric erosion + pretreated dapsone $3 \mathrm{mg} / \mathrm{kg}, 5$. Gastric erosion+ pretreated dapsone $10 \mathrm{mg} / \mathrm{kg}$.

In group 1 animals received only intraperitoneal injection of normal saline without gastric damage. Treated groups in all 3 models received either 1,3 , or $10 \mathrm{mg} / \mathrm{kg}$ intraperitoneal injection of dapsone 30 minutes before gastric damage induction.

After 4 hours of indomethacin and 1 hour of ethanol erosion administration, rats were anesthetized with ketamine (80 mg/kg; i.p.) and xylaxine (8 mg/kg; i.p.), then the stomach was separated and observed for macroscopic evaluation. After that, their blood was collected for measurement of inflammatory factors such as TNF-a and IL1-betausingenzyme-linked immunosorbent assay (ELISA) method.

Finally, the gastric tissues were fixed in buffered formaldehyde for histopathological analysis or restored in $-80^{\circ} \mathrm{C}$ for measurement of myeloperoxidase (MPO) activity.

\section{Assessment of gastric erosions}

Macroscopic assessment: The stomachs were washed with $1 \mathrm{ml}$ of phosphate-buffered. The severity of erosion was examined according to J-Scoring method and the score of each group was determined as the ulcer index. Macroscopic measurements were performed blindly. J-Score for each group was calculated by evaluating the erosions in size order: $(0-1 \mathrm{~mm})$ in diameter $=1 ;(1-2 \mathrm{~mm})=2$; greater than $2 \mathrm{~mm}$ in diameter $=3$. The sum of these measured area in each animal was described as the ulcer index [29].

Microscopic assessment: Histological studies were performed on stomach by hematoxylin and eosin (H\&E) staining method. In brief, tissues were fixed in $10 \%$ of buffered formalin solution for 24 hours, embedded in paraffin wax to form blocks and produced sections into $4 \mu \mathrm{m}$ thicknesses. These sections were hydrated and stained for evaluating morphological damages by a blinded histopathologist. The observation was performed under a light microscope.

\section{Inflammatory Cytokines measurement}


Serum levels of TNF- $\alpha$ and IL-1 $\beta$ were measured by ELISA method using rat tumor necrosis factor a ELISA Kit (RAB0479, Sigma Aldrich, United States) and rat IL-1 $\beta$ ELISA Kit (RAB0277, Sigma Aldrich, United States). Serums were separated by centrifugation at 2500 (xg) for 10 min and then samples were kept in aliquots at $-80^{\circ} \mathrm{C}$ until the time of assay. Serum levels were assessed for TNF- $\alpha$ and IL-1 $\beta$ using (Bio-Tek Synergy HT, US) ELISA plate reader. The levels of TNF- $\alpha$ and IL-1 $\beta$ are presented in $\mathrm{pg} / \mathrm{ml}$.

\section{Measurement of gastric Myeloperoxidase (MPO) activity}

Gastric tissues were used for measurement of MPO activity. Tissues were homogenized by a mechanical homogenizer and centrifuged at $15,000 \mathrm{xg}$ for $20 \mathrm{~min}$. The supernatantswere used for measurement of MPO activity analysis using a plate reader as described by the manufacturer's instruction (Sigma Aldrich, United States). Tissue MPO activities are presented as $\mathrm{U} / \mathrm{g}$ tissue.

\section{Immunohistochemical assessment of P-NF-kB}

The primary and secondary antibodies used were rabbit polyclonal NF-KB p65 (phospho S536) antibody (at 1:100 dilution, Ab 86299, Cambridge, USA) and FITC Goat anti-Rabbit IgG (at 1:200 dilution, Ab 6717, Cambridge, USA), respectively. To evaluation of p-NF-kB protein localization in stomach tissue, $4-\mu \mathrm{m}$ thick paraffin-embedded tissue pieces were deparafinized in xylene. Slides were incubated sequentially overnight at $4 \circ \mathrm{C}$ with primary antibodies and in secondary antibody for $30 \mathrm{~min}$ at room temperature and then washed in PBS. The slides were stained by 4', 6-diamidino-2-phenylindole (DAPI) and immunostained sections were examined using a fluorescence microscope for the staining intensity evaluation. Images were quantified using image j software.

\section{Statistical analysis}

GraphPad Prism (version 9) and Statistical Package for Social Sciences (SPSS) version 22 were used to analysis the data. One way analysis of variance (ANOVA) followed by Tukey's post-hoc were used for data analysis. The results were expressed as the mean \pm SEM and the significance value was set at 0.05 .

\section{Results}

\section{Effect of dapsone on macroscopic damage in ethanol induced peptic erosion}

As illustrated in table 1 hemorrhagic and necrotic area were visible in the gastric mucosa following ethanol administration in control groups $(\mathrm{J}$-score $=61.5 \pm 3.90)$ which was significantly different with normal group $(\mathrm{P}<0.001)$. A remarkable reduction in gastric mucosal damage was observed in group that 
had received dapsone $(10 \mathrm{mg} / \mathrm{kg})(\mathrm{P}<0.001)$. Pre-treatment with $1 \mathrm{mg} / \mathrm{kg}$ dapsone didn't show any significant changes in the gastric erosion area; but a remarkable decrease in $\mathrm{J}$-score was observed in animals subjected to 3 and $10 \mathrm{mg} / \mathrm{kg}$ dapsone $(\mathrm{J}$-score $=42.3 \pm 3.27, \mathrm{P}<0.05$; and $\mathrm{J}$-score $=20.16 \pm 1.097$ $\mathrm{P}<0.001$, respectively).

Table 1

Comparison of J-Score (macroscopic score) between control and dapsone treated groups in rats. Data

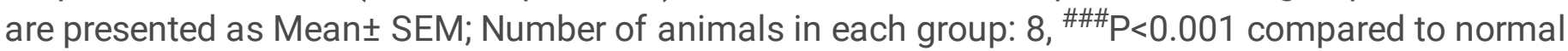
group, ${ }^{*} \mathrm{P}<0.05 ;{ }^{* *} \mathrm{P}<0.01 ;{ }^{* * *} \mathrm{P}<0.001$ compared to relative control group.

\begin{tabular}{|llll|}
\hline GROUPS & $\begin{array}{l}\text { ALCOHOL-induced } \\
\text { gastric erosion }\end{array}$ & $\begin{array}{l}\text { INDOMETHACIN-induced } \\
\text { gastric erosion }\end{array}$ & $\begin{array}{l}\text { STRESS-induced } \\
\text { gastric erosion }\end{array}$ \\
\hline Normal & 0 & 0 & 0 \\
\hline Control & $61.5 \pm 3.90 \# \#$ & $43.1 \pm 4.99 \# \# \#$ & $34.66 \pm 4.68$ \#\# \\
\hline $\begin{array}{l}\text { Dapsone } 1 \\
\text { mg/kg }\end{array}$ & $56 \pm 5.46$ & $36.16 \pm 5.62$ & $29.16 \pm 3.71$ \\
\hline $\begin{array}{l}\text { Dapsone } 3 \\
\text { mg/kg }\end{array}$ & $42.3 \pm 3.27 *$ & $29 \pm 5.20$ & $18.83 \pm 2.01$ ** \\
$\begin{array}{l}\text { Dapsone } 10 \\
\text { mg/kg }\end{array}$ & $20.16 \pm 1.097 * * *$ & $15 \pm 2.06 * *$ & $7.16 \pm 0.87 * * *$ \\
\hline
\end{tabular}

\section{Effect of dapsone on macroscopic damage in stress induced peptic erosion}

As shown in table 1 the water-immersion stress was associated with focal hemorrhagic lesions in the control group $(\mathrm{J}$-score $=34.66 \pm 4.68)$ compared to normal group $(\mathrm{P}<0.001)$. But administration of dapsone ( 3 and $10 \mathrm{mg} / \mathrm{kg}$ ) before stress particularly at dose of $10 \mathrm{mg} / \mathrm{kg}$, markedly abolished the gastric lesions in comparison with control untreated group $(P<0.01$ and $P<0.001$, respectively).

Administration of dapsone $(1 \mathrm{mg} / \mathrm{kg})$ failed to significantly affect the severity of erosions in comparisons to control.

\section{Effect of dapsone on macroscopic damage in indomethacin-induced gastric damage}

As demonstrated in table 1 indomethacin led to formation of multiple mucosal erosions in the control groups compare to normal group $(\mathrm{P}<0.001)$. On the contrary, According to Table1, the $\mathrm{J}$-score in control 
rats exposed to indomethacin reached $43.1 \pm 4.99$, which is markedly higher than rats that did not receive indomethacin. Pre-treatment with $10 \mathrm{mg} / \mathrm{kg}$ dapsone was protective against indomethacin-induced gastric damage ( $\mathrm{J}$-score $=15 \pm 2.06, \mathrm{P}<0.01$ ). Pre-treatment with dapsone at doses of 1 and $3 \mathrm{mg} / \mathrm{kg}$ did not show any significant protective effects on gastric lesions.

\section{Histopathological assessment of gastric tissue}

Fig. 1a shows the histological features of the gastric mucosa in a normal rat. Histological examination of the gastric tissues in all control rats in all 3 models showed severe chronic active gastritis with mucosal erosion (Fig. 1b, 1d, and 1f) in comparison with normal group (Pख0.01). The results showed that treatment with dapsone $(10 \mathrm{mg} / \mathrm{kg}$ ) improved mucosal congestion in the body of the stomach (as shown in Fig. 1c, 1g). Dapsone (10 mg/kg) treatment in ethanol and indomethacin-induced ulcerated rats showed mild submucosal erosions (about $1 / 3$ and less than $1 / 4$ of the mucosal thickness, respectively. In Fig. 1e, dapsone (10 mg/kg) treatment in stress- induced ulcerated rats showed normal histopathology without significant superficial mucosal epithelial degeneration.

\section{Effect of dapsone on plasma inflammatory cytokines}

In order to evaluation of inflammatory response, TNF- $\alpha$ and IL-1 $\beta$, as the inflammatory factors, in serum of animals were detected by ELISA. There was a high serum level of TNF- $\alpha$ and IL- $1 \beta$ in the ethanol-, stress-, and indomethacin- induced

gastric erosion groups as compared with normal group $(\mathrm{P} \otimes 0.001)$. Among the tested doses, high dose of dapsone (10 mg/kg, i.p.) showed a reduction on serum concentration of TNF- $\alpha$ and IL-1 $\beta$ in all three models.

As demonstrated in Fig. $2 a$ and $2 b$, the increased TNF- $a$ and IL-1 $\beta$ levels in ethanol-induced gastric erosion group was significantly reduced after administration of dapsone $(10 \mathrm{mg} / \mathrm{kg} ; \mathrm{P}<0.001$ and $\mathrm{P}<0.05$; respectively). But with lower doses of dapsone (1, and $3 \mathrm{mg} / \mathrm{kg})$, the levels of TNF- $a$ and IL-1 $\beta$ did not change statistically.

In water immersion stress groups (Fig. 3a and 3b), a statistically significant decrease in serum concentration of TNF-a was observed in both higher doses of dapsone ( 3 and $10 \mathrm{mg} / \mathrm{kg}$ ) as compared to the control group $(P<0.01$ and $P<0.001$, respectively). With regard to serum IL-1 $\beta$ concentration, dapsone could only reduce it at the highest dose $10 \mathrm{mg} / \mathrm{kg}(P<0.01)$.

In the indomethacin induced erosion groups (Fig. 4a, 4b), rats pretreated with both doses of 3 and 10 $\mathrm{mg} / \mathrm{kg}$ of dapsone showed remarkable lower serum concentration of TNF-a $(P<0.05$ and $P<0.001$, respectively). Only administration of dapsone $(10 \mathrm{mg} / \mathrm{kg})$ exhibited a significant reduction in serum level of IL-1 $\beta$ when compared to the indomethacin induced erosion group $(P<0.05)$. 


\section{Effect of dapsone on MPO activity}

Based on Fig. 5, the tissue amount of MPO in the control groups was increased following induction of gastric erosion compared to the normal groups $(p<0.001)$. In both ethanol and indomethacin-induced erosion groups, a significant reduction in gastric MPO activity was observed in dapsone-treated groups (3 and $10 \mathrm{mg} / \mathrm{kg}$ ) in

comparison with the control group ( $P<0.05, P<0.01$, respectively). However, the level of MPO in stressinduced gastric erosion groups was slightly decreased $(P<0.05)$ compared with ethanol and indomethacin-induced gastritis groups $(P<0.01)$ following dapsone $10 \mathrm{mg} / \mathrm{kg}$ treatment. (Fig. 5$)$ indicates that treatment with dapsone $(10 \mathrm{mg} / \mathrm{kg}$ ) led to a more significant decrease in gastric MPO level of all three models. On the other hand, the result revealed an inhibitory effect of dapsone (especially at dose of $10 \mathrm{mg} / \mathrm{kg}$ ) on MPO activity as a marker of neutrophil infiltration.

\section{Effect of dapsone on NF-KB expression}

We performed immunohistochemistry in order to determine the expression level of NF-kB protein in all three gastric erosion models (Fig. 6). In all control groups the NFKB protein expression was significantly raised in comparing to the normal groups. In ethanol-induced gastric erosion model based on results achieved from IHC staining method, the expression of this protein was dramatically decreased in the dapsone $10 \mathrm{mg} / \mathrm{kg}$ treated group in comparison with the control (ethanol-induced) group $(P<0.001)$. In the same manner, pretreatment with $10 \mathrm{mg} / \mathrm{kg}$ dapsone revealed a significant decrease in NF-kB expression compared to the control group in stress-induced peptic erosion (Fig. 7$)(P<0.001)$. According to (Fig. 8), similar to the previous two models, in the indomethacin-induced gastric erosion model remarkable reduction of NF-KB expression in dapsone $10 \mathrm{mg} / \mathrm{kg}$ treated group was detected $(P<0.001)$.

\section{Discussion}

In the present study, the gastro-protective effects of dapsone in three different rat models of peptic erosion were demonstrated. Three different doses of dapsone $(1,3$,

and $10 \mathrm{mg} / \mathrm{kg}$ ) were administered intraperitoneally before gastric erosion induction. According to the results of this research, dapsone at a dose of $1 \mathrm{mg} / \mathrm{kg}$ showed no significant protective effect in all three experimental models but at the doses of $3 \mathrm{mg} / \mathrm{kg}$ and specially $10 \mathrm{mg} / \mathrm{kg}$, the effects of dapsone on reduction of mucosal erosions ( $\mathrm{J}$ score), histopathological damages, as well as inflammatory factors were evident.

Studies have shown that ethanol can indirectly induce destructive effects in submucosal venules through leukotriene C4 (LTC4) over production [13]. Also it was reported that dapsone can inhibit the synthesis of leukotrienes [23], therefore it may suppress following inflammation. Various reports have proved that free radical formation and oxidative stress pathways play a critical role in the process of inflammation and 
can accelerate gastric injury following ethanol administration [30]. Reactive oxygen species (ROS), which are produced by inflammatory cells such as active neutrophils, enhance the severity of damages and cause concomitant increase in MPO activity which is considered as an indicator of neutrophil infiltration [31]. In agreement with previous reports, our study showed that the level of gastric MPO was increased remarkably after 1 hour of oral ethanol gavage in control group, but pretreatment with $10 \mathrm{mg} / \mathrm{kg}$ dapsone resulted in a significant decrease in MPO activity. In our previous study, reduction in the activity of myeloperoxidase due to dapsone administration have been exhibited in an animal model of renal ischemia reperfusion injury [32]. NF-KB is a transcription factor that facilitates essential inflammatory process in ethanol-induced gastric injury including the expression of several proinflammatory factors such as TNF-a and IL-8 [33]. NFKB contains of p65

and p50 subunits although NFkB-p65 subunit has been considered as an indicator for NFkB activation [34]. In recent studies, compounds that decreased the expression of NF-KB have been observed to be useful in the attenuation of gastric erosion [35]. Besides, ethanol administration can provoke a great number of proinflammatory cytokines generation such as IL-1 $\beta$ and TNF- $\alpha[36,37]$. IL-1 $\beta$ induce macrophage infiltration and ICAM-1 over expression [38]. Moreover, TNF- $a$ can suppresses gastric microcirculation and upregulate NF-KB expression [39], as well as adhesion molecules production [40]. We observed an increase amount of NF-KB protein expression as well as IL-1 $\beta$, and TNF-a serum level following ethanol gavage in accordance with previous studies. Dehpour et al. have been shown previously that dapsone can decrease the level of IL-1 $\beta$, and TNF- $a$ in different animal inflammatory models $[32,41,42]$. Data of this study demonstrated that dapsone only at dose of $10 \mathrm{mg} / \mathrm{kg}$ showed a significant decrease in of these inflammatory markers in ethanol induced gastric erosion.

In the pathophysiology of stress induced ulcer, oxidative damage and excessive generation of ROS [43], production of proinflammatory cytokines (such as TNF- $a, \mathrm{IL}-1 \beta$ and IL-6) and infiltration of neutrophils [44] are involved following local hypoxia and ischemia. Recent studies have shown that TNF-a, IL-1 $\beta$ can lead to delayed healing of gastric ulcers [45]. Most of these inflammatory cytokines are downstream mediators of NF-KB pathway that is reported p65 subunit of NF-KB plays a critical role in response to stress by stimulating the expression of specific genes [46]. In this study water immersion restraint enhanced TNF- $\alpha$, IL-1 $\beta$, and NF-KB activity. In addition, it has been found that dapsone have antiinflammatory properties

through down regulation of NF-kB pathway in a rat model of colitis [47]. The present study demonstrated that dapsone reduced mucosal injury of the stomach tissue and $\mathrm{J}$ score mean in a dose dependent manner in stress erosion. Although this should be taken into consideration that in microscopic study and $\mathrm{J}$ score evaluation, gastric damage resulted from stress showed lower intensity. In addition, we found that, dapsone attenuates stress induced erosion by suppressing of inflammatory cascades mediators. Our data are consistent with a study which report dapsone can inhibit human leukocyte enzyme MPO production, and this inhibition is depends on various factors such as dapsone concentration [48]. 
As mentioned in previous studies, NSAIDs have inhibitory effects on cyclooxygenase enzymes and subsequently prevent synthesis of protective mucosal prostaglandins. PGE2 could reduce TNF- $a$ and IL-1 release from macrophages and leukotriene B4 [49]. Accumulated evidence show the ability of indomethacin to stimulate NF-KB expression and subsequently up regulation of its promoting downstream cytokines such as TNF- $\alpha$ and IL-1 [50-52]. Furthermore, an increase in gastric MPO level, indicates neutrophil infiltration during indomethacin-induced gastric injury [53]. Increased gastric mucosal permeability following disruption in mucosal barriers, leads to microbial invasion, neutrophil chemotaxis and inflammation [54]. Pretreatment with $10 \mathrm{mg} / \mathrm{kg}$ dapsone, resulted in a significant decrease in the level of MPO, TNF-a, and IL-1 $\beta$ as compared to control groups. In addition, dapsone prevented NF-KB expression and formation of gastric erosions in this model.

Since inflammatory pathways are highly involved in causing and advancing gastric ulcer [15], compounds with antioxidant and anti-inflammatory properties may

represent protective roles in development of gastric injuries and erosions. A vast majority of antiinflammatory drugs such as corticosteroids or NSAIDs have been shown to breed gastric destruction $[3,4]$ whereas dapsone showed gastro-protective effects via inhibition of inflammatory cascades, in this study. This protection may be related to different anti-inflammatory properties of dapsone compared to mentioned drugs.

\section{Conclusions}

In summary, dapsone exhibits gastro-protective effects against 3 different causes of gastric mucosal damage namely ethanol, water-immersion stress, and indomethacin. According to present study, the effects of dapsone seems to be associated with a decrease in inflammatory markers (TNF-a, and IL-1 $\beta$, and NF-KB) and gastric leukocyte infiltration which might be related to anti-inflammatory effects of dapsone. Nevertheless, further research is needed to distinguish the exact protective mechanisms of dapsone.

\section{Declarations}

\section{Ethics approval}

The Ethical Committee of Tehran University of Medical Sciences, approved all experiment details and animal study. (IR.TUMS.VCR.REC.1398.225).

\section{Consent for publication}

'Not applicable' 


\section{Availability of data and material}

The data are available from the corresponding author upon reasonable request.

\section{Competing interests}

The authors declare that they have no competing interests

\section{Funding}

This work was supported by Experimental Medicine Research Center, Tehran University of Medical Sciences, Tehran, Iran under Grant (number. 98-01-158-41826).

\section{Authors' contributions}

Mohammad Sheibani: Co-designed the study, performed experiments, analysed data, co-wrote the paper. Sadaf Nezamoleslami: Co-designed the study, performed experiments, analysed data, co-wrote the paper. Nastaran Rahimi: Performed experiments, co-wrote the paper. Ata Abbasi: Histopathological analysis. Ahmad Reza Dehpour: Supervised the research, designed the experiments. All authors read and approved the final manuscript.

\section{Acknowledgements}

The authors thank Gilaranco Pharmaceutical Co. (Rasht, Iran) for gift of dapsone powder. This work was supported by Experimental Medicine Research Center, Tehran University of Medical Sciences, Tehran, Iran under Grant (number. 98-01-158-41826).

\section{References}

1. Malfertheiner P, Chan FK, McColl KE. Peptic ulcer disease. The Lancet. 2009;374:1449-61.

2. Susser M, Stein Z. Civilisation and peptic ulcer. The Lancet. 1962;279:116-9.

3. Huang J-Q, Sridhar S, Hunt RH. Role of Helicobacter pylori infection and non-steroidal antiinflammatory drugs in peptic-ulcer disease: a meta-analysis. The Lancet. 2002;359:14-22.

4. Piper JM, Ray WA, Daugherty JR, Griffin MR. Corticosteroid use and peptic ulcer disease: role of nonsteroidal anti-inflammatory drugs. Ann Intern Med. 1991;114:735-40.

5. Chou SP. An examination of the alcohol consumption and peptic ulcer association-Results of a national survey. Alcoholism: Clinical Experimental Research. 1994;18:149-53.

6. Ramakrishnan K, Salinas RC. Peptic ulcer disease. American family physician 2007, 76. 
7. Collier DS, Pain J. Non-steroidal anti-inflammatory drugs and peptic ulcer perforation. Gut. 1985;26:359-63.

8. Warzecha Z, Ceranowicz P, Dembinski M, Cieszkowski J, Ginter G, Ptak-Belowska A, Dembinski A. Involvement of cyclooxygenase- 1 and cyclooxygenase-2 activity in the therapeutic effect of ghrelin in the course of ethanol-induced gastric ulcers in rats. J Physiol Pharmacol. 2014;65:95-106.

9. Warzecha Z, Dembiński A, Ceranowicz P, Konturek SJ, Tomaszewska R, Stachura J, Nakamura T, Konturek PC. Inhibition of cyclooxygenase-2 reduces the protective effect of hepatocyte growth factor in experimental pancreatitis. Eur J Pharmacol. 2004;486:107-19.

10. Brzozowski T, Konturek P, Konturek S, Pajdo R, Schuppan D, Drozdowicz D, Ptak A, Pawlik M, Nakamura T, Hahn E. Involvement of cyclooxygenase (COX)-2 products in acceleration of ulcer healing by gastrin and hepatocyte growth factor. Journal of Physiology and Pharmacology 2000, 51.

11. Sørbye H, Svanes K. The role of blood flow in gastric mucosal defence, damage and healing. Dig Dis. 1994;12:305-17.

12. Hollander D, Tarnawski A, Krause WJ, Gergely H. Protective effect of sucralfate against alcoholinduced gastric mucosal injury in the rat: macroscopic, histologic, ultrastructural, and functional time sequence analysis. Gastroenterology. 1985;88:366-74.

13. Oates PJ, Hakkinen JP. Studies on the mechanism of ethanol-induced gastric damage in rats. Gastroenterology. 1988;94:10-21.

14. Plummer MP, Blaser AR, Deane AM. Stress ulceration: prevalence, pathology and association with adverse outcomes. Crit Care. 2014;18:213.

15. Lanas A, Chan FK. Peptic ulcer disease. The Lancet. 2017;390:613-24.

16. Mahmood A, Al-Bayaty F, Salmah I, AB NS, Harita H. Enhancement of gastric ulcer by Areca catechu nut in ethanol-induced gastric mucosal injuries in rats. Journal of Medicinal Plants Research. 2011;5:2462-9.

17. Suzuki H, Nishizawa T, Tsugawa H, Mogami S, Hibi T. Roles of oxidative stress in stomach disorders. Journal of clinical biochemistry and nutrition 2011:1112080129-1112080129.

18. Soll AH. Pathogenesis of peptic ulcer and implications for therapy. N Engl J Med. 1990;322:909-16.

19. Farrar J, Hotez PJ, Junghanss T, Kang G, Lalloo D, White NJ: Manson's Tropical Diseases E-Book: Expert Consult-Online and Print. Elsevier Health Sciences; 2013.

20. Wozel G, Blasum C. Dapsone in dermatology and beyond. Arch Dermatol Res. 2014;306:103-24.

21. Lewis AJ, Gemmell DK, Stimson WH. The anti-inflammatory profile of dapsone in animal models of inflammation. Agents actions. 1978;8:578-86.

22. Debol SM, Herron MJ, Nelson RD. Anti-inflammatory action of dapsone: inhibition of neutrophil adherence is associated with inhibition of chemoattractant-induced signal transduction. J Leukoc Biol. 1997;62:827-36.

23. Bonney RJ, Humes JL. Physiological and pharmacological regulation of prostaglandin and leukotriene production by macrophages. J Leukoc Biol. 1984;35:1-10. 
24. Wozel G, Barth J. Current aspects of modes of action of dapsone. International journal of dermatology. 1988;27:547-52.

25. Kettle AJ, Winterbourn CC. Mechanism of inhibition of myeloperoxidase by anti-inflammatory drugs. Biochem Pharmacol. 1991;41:1485-92.

26. Hajrezaie M, Salehen N, Karimian H, Zahedifard M, Shams K, Al Batran R, Majid NA, Khalifa SA, Ali $\mathrm{HM}$, El-Seedi $\mathrm{H}$. Biochanin a gastroprotective effects in ethanol-induced gastric mucosal ulceration in rats. PloS one. 2015;10:e0121529.

27. Warzecha Z, Dembinski A, Brzozowski T, Ceranowicz P, Dembinski M, Stachura J, Konturek S. Histamine in stress ulcer prophylaxis in rats. Journal of physiology and pharmacology 2001, 52.

28. Bhattacharya S, Chaudhuri SR, Chattopadhyay S, Bandyopadhyay SK. Healing properties of some Indian medicinal plants against indomethacin-induced gastric ulceration of rats. Journal of Clinical Biochemistry Nutrition. 2007;41:106-14.

29. Dehpour AR, Mani AR, Amanlou M, Nahavandi A, Amanpour S, Bahadori M. Naloxone is protective against indomethacin-induced gastric damage in cholestatic rats. Journal of gastroenterology. 1999;34:178-81.

30. Hernández-Muñoz R, Montiel-Ruíz C, Vázquez-Martínez O. Gastric mucosal cell proliferation in ethanol-induced chronic mucosal injury is related to oxidative stress and lipid peroxidation in rats. Lab Invest. 2000;80:1161.

31. Lee M-Y, Shin I-S, Jeon W-Y, Seo C-S, Ha H, Huh J-I, Shin H-K. Protective effect of Bojungikki-tang, a traditional herbal formula, against alcohol-induced gastric injury in rats. J Ethnopharmacol. 2012;142:346-53.

32. Nezamoleslami S, Sheibani M, Jahanshahi F, Mumtaz F, Abbasi A, Dehpour AR. Protective effect of dapsone against renal ischemia-reperfusion injury in rat. Immunopharmacol Immunotoxicol. 2020;42:272-9.

33. Arab HH, Salama SA, Omar HA, Arafa E-SA, Maghrabi IA. Diosmin protects against ethanol-induced gastric injury in rats: novel anti-ulcer actions. PloS one 2015, 10.

34. Verma S, Kumar VL. Attenuation of gastric mucosal damage by artesunate in rat: modulation of oxidative stress and NFKB mediated signaling. Chemico-Biol Interact. 2016;257:46-53.

35. Al Asmari A, Al Shahrani H, Al Masri N, Al Faraidi A, Elfaki I, Arshaduddin M. Vanillin abrogates ethanol induced gastric injury in rats via modulation of gastric secretion, oxidative stress and inflammation. Toxicology reports. 2016;3:105-13.

36. Rozza AL, de Faria FM, Brito ARS, Pellizzon CH. The gastroprotective effect of menthol: involvement of anti-apoptotic, antioxidant and anti-inflammatory activities. PloS one. 2014;9:e86686.

37. Zheng Y-F, Xie J-H, Xu Y-F, Liang Y-Z, Mo Z-Z, Jiang W-W, Chen X-Y, Liu Y-H, Yu X-D, Huang P. Gastroprotective effect and mechanism of patchouli alcohol against ethanol, indomethacin and stress-induced ulcer in rats. Chem Biol Interact. 2014;222:27-36.

38. Watanabe T, Higuchi K, Tominaga K, Fujiwara Y, Arakawa T. Acid regulates inflammatory response in a rat model of induction of gastric ulcer recurrence by interleukin 1 $\beta$. Gut. 2001;48:774-81. 
39. Li W, Huang H, Niu X, Fan T, Mu Q, Li H. Protective effect of tetrahydrocoptisine against ethanolinduced gastric ulcer in mice. Toxicol Appl Pharmcol. 2013;272:21-9.

40. Arab HH, Salama SA, Omar HA, Arafa E-SA, Maghrabi IA. Diosmin protects against ethanol-induced gastric injury in rats: novel anti-ulcer actions. PloS one. 2015;10:e0122417.

41. Dejban P, Rahimi N, Takzare N, Jahansouz M, Haddadi N-S, Dehpour AR. Beneficial effects of dapsone on ischemia/reperfusion injury following torsion/detorsion in ipsilateral and contralateral testes in rat. Theriogenology. 2019;140:136-42.

42. Sheibani M, Nezamoleslami S, Faghir-Ghanesefat $H$, hossein Emami A, Dehpour AR. Cardioprotective effects of dapsone against doxorubicin-induced cardiotoxicity in rats. Cancer Chemother Pharmacol. 2020;85:563-71.

43. Yasukawa K, Kasazaki K, Hyodo F, Utsumi H. Non-invasive analysis of reactive oxygen species generated in rats with water immersion restraint-induced gastric lesions using in vivo electron spin resonance spectroscopy. Free Radic Res. 2004;38:147-55.

44. Hamaguchi M, Watanabe T, Higuchi K, Tominaga K, Fujiwara Y, Arakawa T. Mechanisms and roles of neutrophil infiltration in stress-induced gastric injury in rats. Digestive diseases sciences. 2001;46:2708-15.

45. Chauhan I, Agrawal S, Goel RK. Status of inflammatory markers and growth factor in gastric ulcer protective effects of Punica granatum L. peel extract in rat. National Journal of Physiology Pharmacy Pharmacology. 2018;8:12-7.

46. Jia Y-T, Ma B, Wei W, Xu Y, Wang Y, Tang H-T, Xia Z-F. Sustained activation of nuclear factor-kB by reactive oxygen species is involved in the pathogenesis of stress-induced gastric damage in rats. Critical care medicine. 2007;35:1582-91.

47. Rashidian A, Rashki A, Abdollahi A, Haddadi N-S, Chamanara M, Mumtaz F, Dehpour AR. Dapsone reduced acetic acid-induced inflammatory response in rat colon tissue through inhibition of NF-kB signaling pathway. Immunopharmacol Immunotoxicol. 2019;41:607-13.

48. Bozeman PM, Learn DB, Thomas EL. Inhibition of the human leukocyte enzymes myeloperoxidase and eosinophil peroxidase by dapsone. Biochem Pharmacol. 1992;44:553-63.

49. Martin GR, Wallace JL. Gastrointestinal inflammation: a central component of mucosal defense and repair. Experimental Biology Medicine. 2006;231:130-7.

50. Takahashi S, Fujita T, Yamamoto A. Role of nuclear factor-кB in gastric ulcer healing in rats. American Journal of Physiology-Gastrointestinal Liver Physiology. 2001;280:G1296-304.

51. Yadav SK, Adhikary B, Chand S, Maity B, Bandyopadhyay SK, Chattopadhyay S. Molecular mechanism of indomethacin-induced gastropathy. Free radical biology medicine. 2012;52:1175-87.

52. Katary M, Salahuddin A. Gastroprotective effect of vanillin on indomethacin-induced gastric ulcer in rats: protective pathways and anti-Secretory mechanism. Clin Exp Pharmacol. 2017;7:21611459.1000232.

53. Kataoka H, Horie Y, Koyama R, Nakatsugi S, Furukawa M. Interaction between NSAIDs and steroid in rat stomach. Digestive diseases sciences. 2000;45:1366-75. 
54. Matsui H, Shimokawa O, Kaneko T, Nagano Y, Rai K, Hyodo I. The pathophysiology of non-steroidal anti-inflammatory drug (NSAID)-induced mucosal injuries in stomach and small intestine. Journal of clinical biochemistry nutrition. 2011;48:107-11.

\section{Figures}
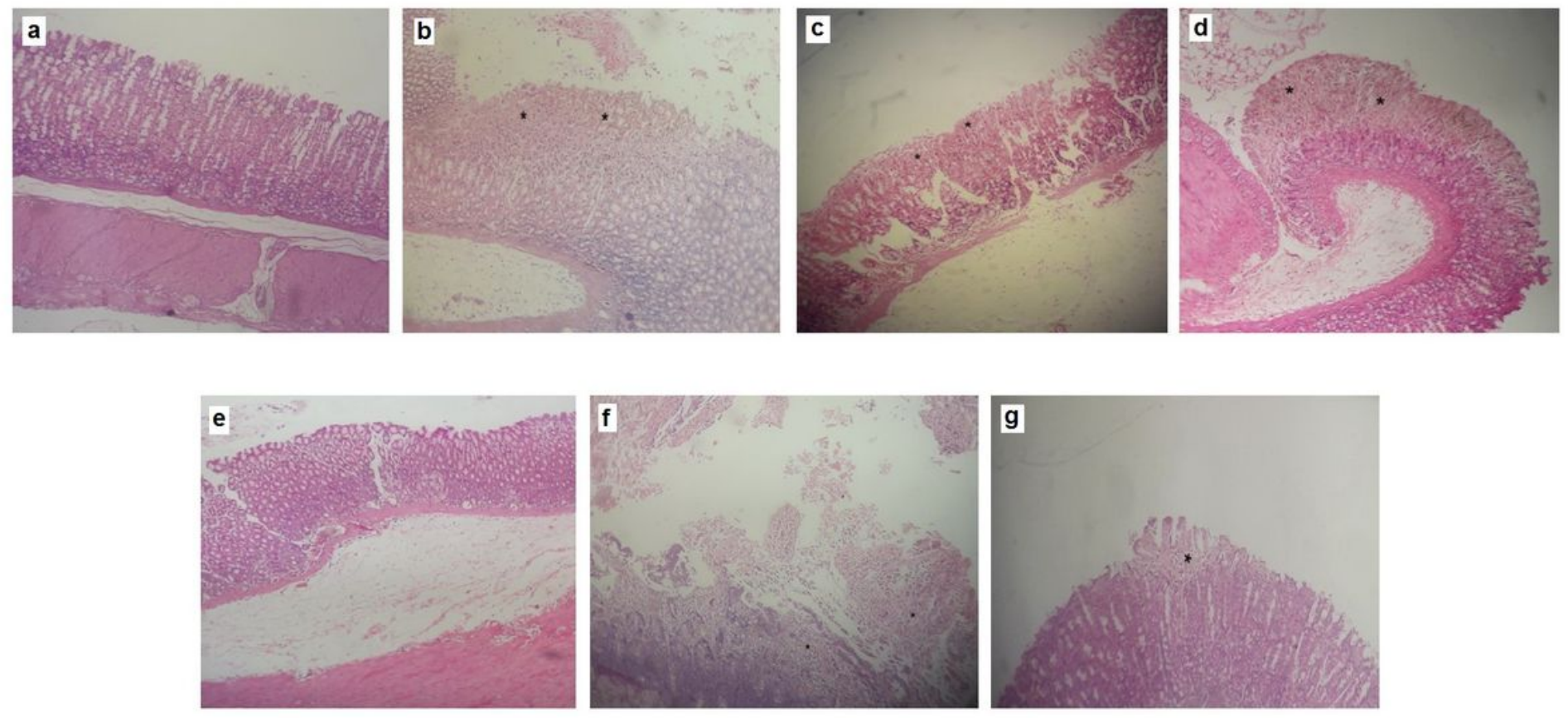

\section{Figure 1}

Effects of dapsone on histopathological lesions in gastric injury of rats exposed to ethanol, stress, and indomethacin. Slices stained with H\&E (20x). (a) Gastric mucosa of a normal rat. (b) Ethanol induced erosion tissues showed active gastritis with mucosal erosion (more than 1/2 of the mucosal thickness shown by *). (c) The ethanol /dapsone (10 mg/ $\mathrm{kg}$ ) group showed active gastritis with mucosal erosion (about $1 / 3$ of the mucosal thickness shown by *). (d) Stress induced erosion tissues showed severe mucosal erosion with intramucosal hemorrhage (more than $1 / 2$ of the mucosal thickness shown by *).

(e) The stress / dapsone (10 mg/kg) group showed normal histopathology without significant pathologic changes (f) The black star in the indomethacin received group showed deep mucosal erosion in the body of stomach (more than $2 / 3$ of the mucosal thickness). Pathological changes with $10 \mathrm{mg} / \mathrm{kg}$ dapsone treatment. $(\mathrm{g})$ The black stars in the indomethacin/ dapsone $(10 \mathrm{mg} / \mathrm{kg})$ group showed mild active gastritis with superfacial erosion (less than $1 / 4$ of the mucosa thickness, shown by*). 
TNF-alpha (ethanol-induced ulcer)

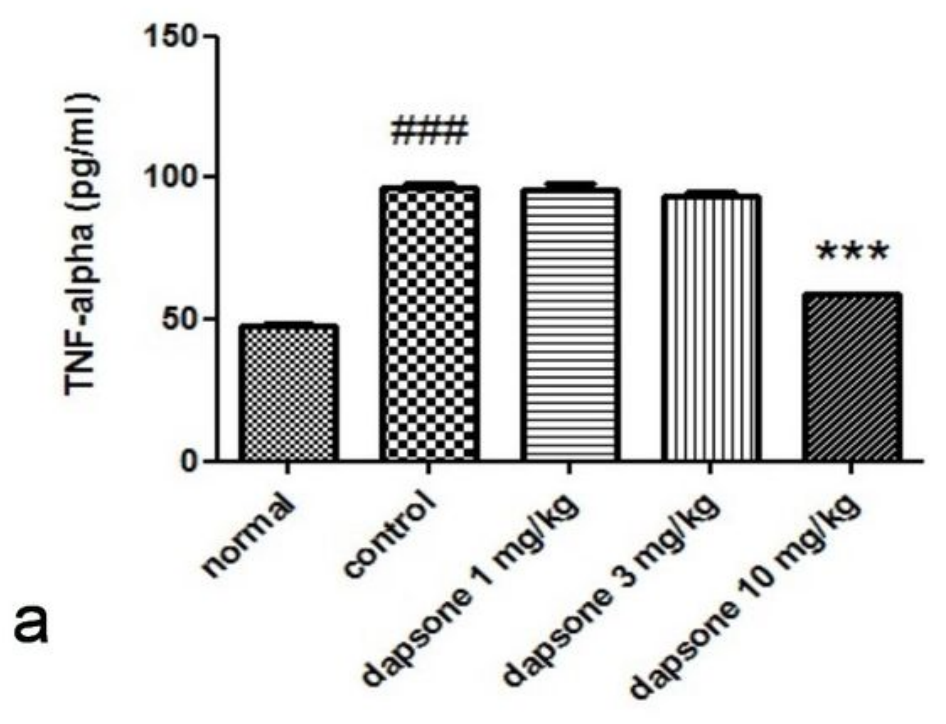

\section{IL-1ß (ethanol-induced ulcer)}

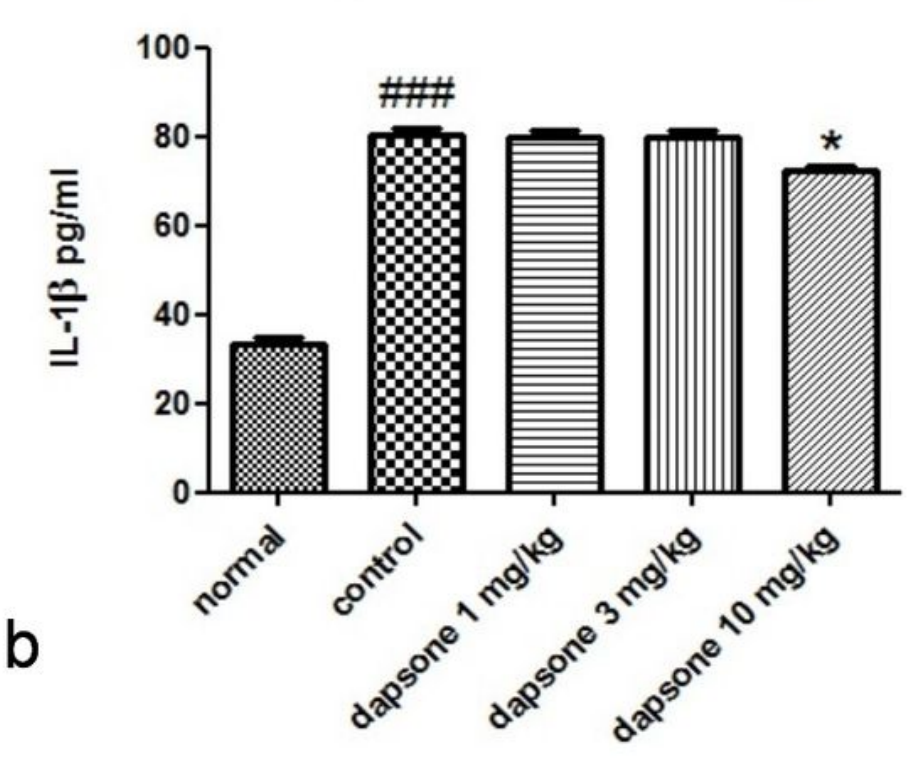

Figure 2

Serum levels of TNF- $a(a)$ and IL-1 $\beta$ (b) in ethanol-induced erosion group. Results are expressed as mean $\pm S E M$; Number of animal in each group: $8, \# \# \# P<0.001$, compared to normal group; ${ }^{*} P<0.05, * \star \star P<$ 0.001 , compared to control group 
TNF-alpha (stress-induced ulcer)

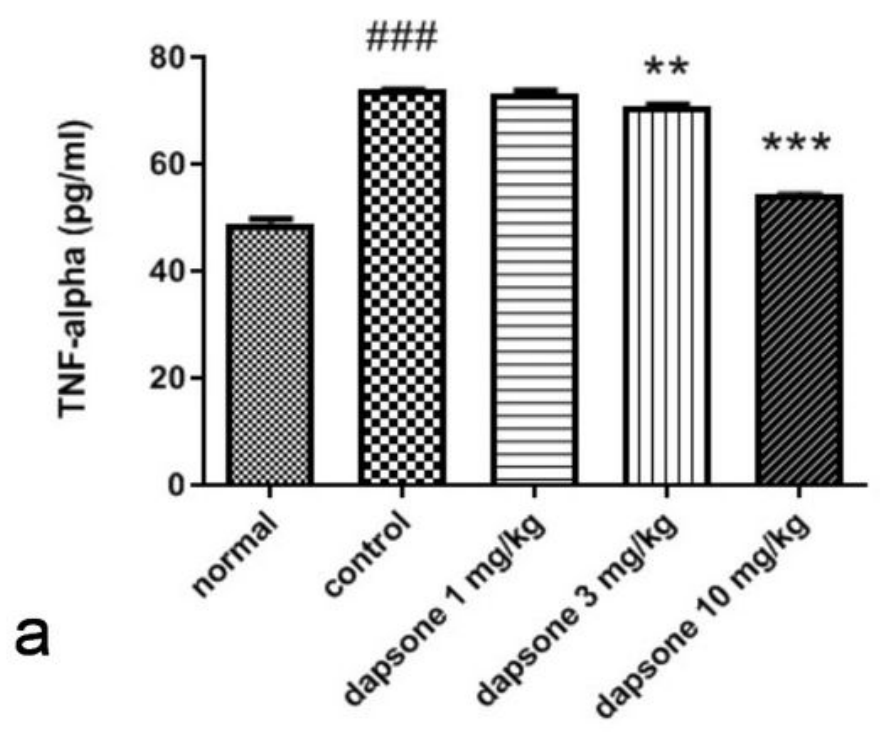

\section{IL-1 $\beta$ (stress-induced ulcer)}

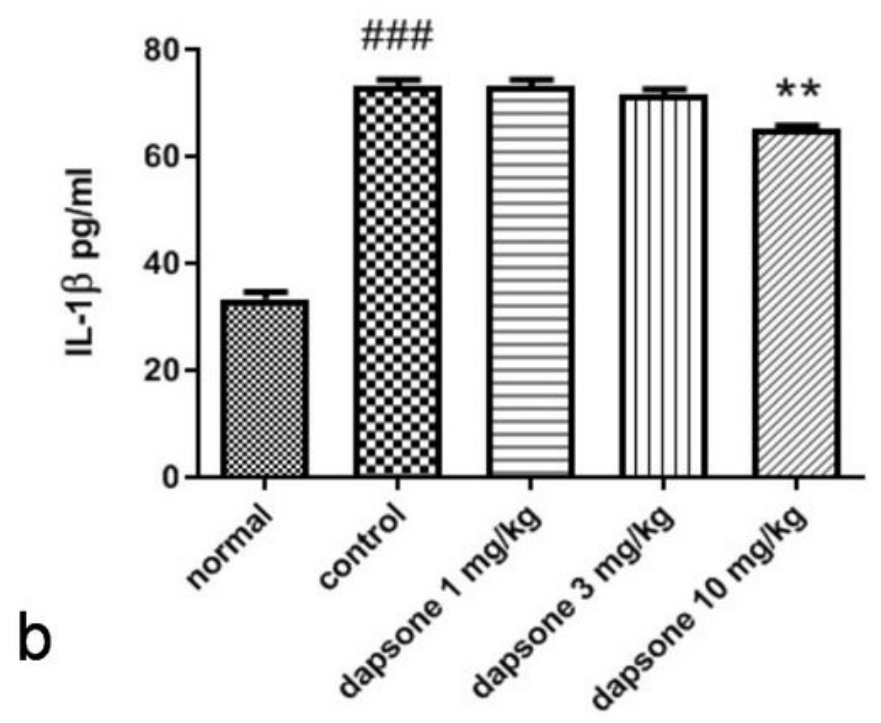

Figure 3

Serum levels of TNF- $a(a)$ and IL-1 $\beta$ (b) in stress-induced erosion group. Results are expressed as mean $\pm S E M$; Number of animal in each group: 8 , \#\#\#P<0.001, compared to normal group; ${ }^{\star \star} P<0.01$, $\star \star * * P<0.001$, compared to control group 
TNF-alpha (indomethacin-induced ulcer)

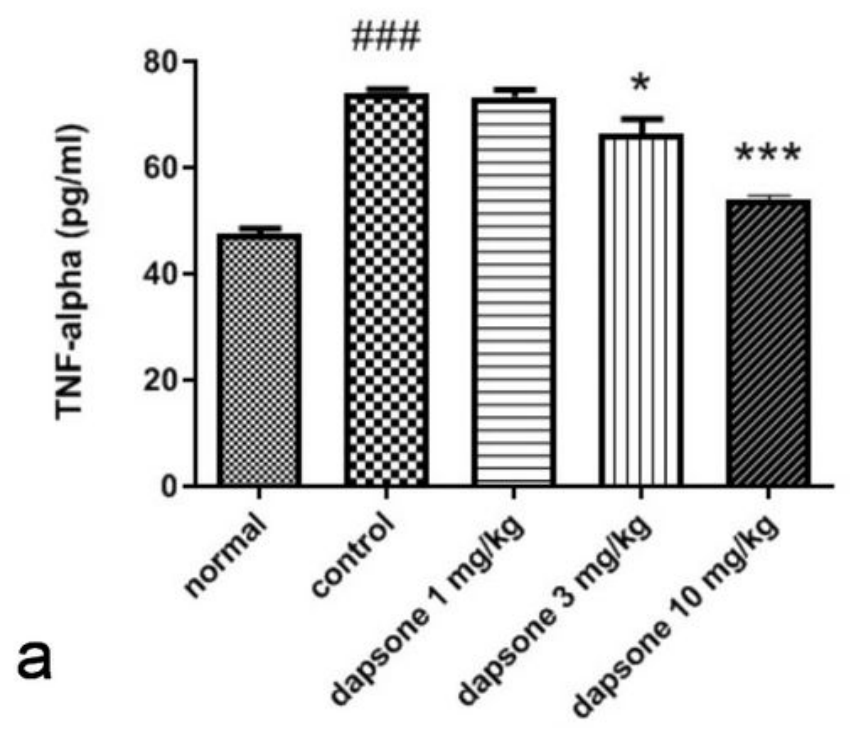

\section{IL-1 $\beta$ (indomethacin-induced ulcer)}

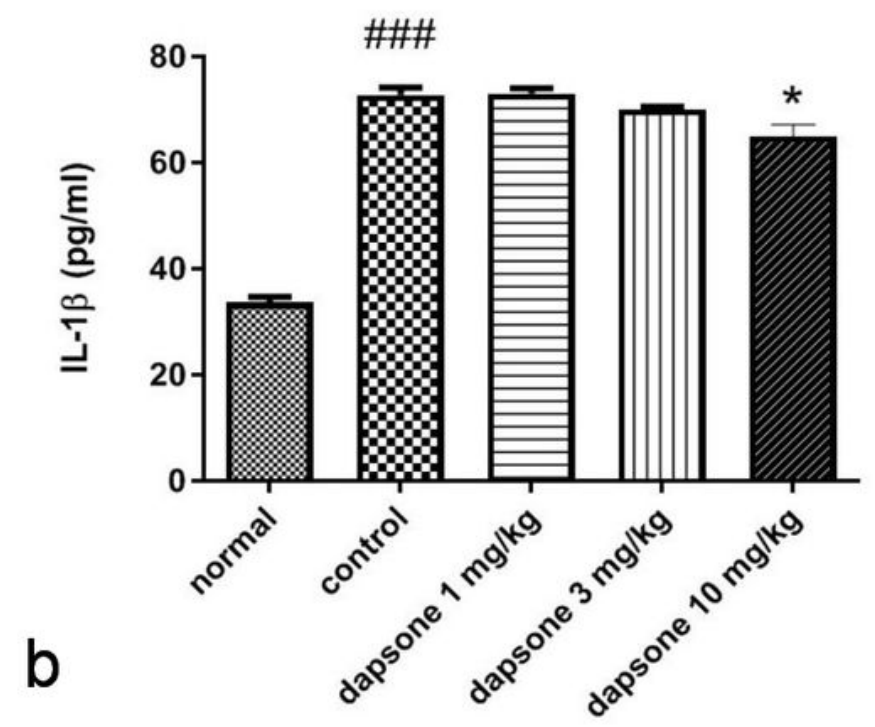

Figure 4

Serum levels of TNF-a (a) and IL-1 $\beta$ (b) in indomethacin-induced erosion group. Results are expressed as mean $\pm S E M$; Number of animal in each group: $8, \# \# \# P<0.001$, control compared to normal group; ${ }^{*} \mathrm{P}<$ $0.05,{ }^{\star * *} \mathrm{P}<0.001$, compared to control group 
Myeloperoxidase (ethanol-induced ulcer)

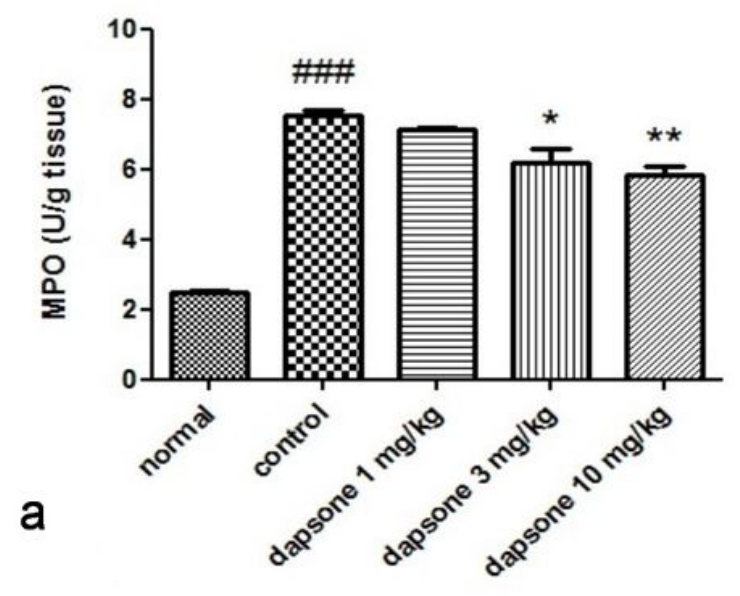

Myeloperoxidase (stress-induced ulcer)

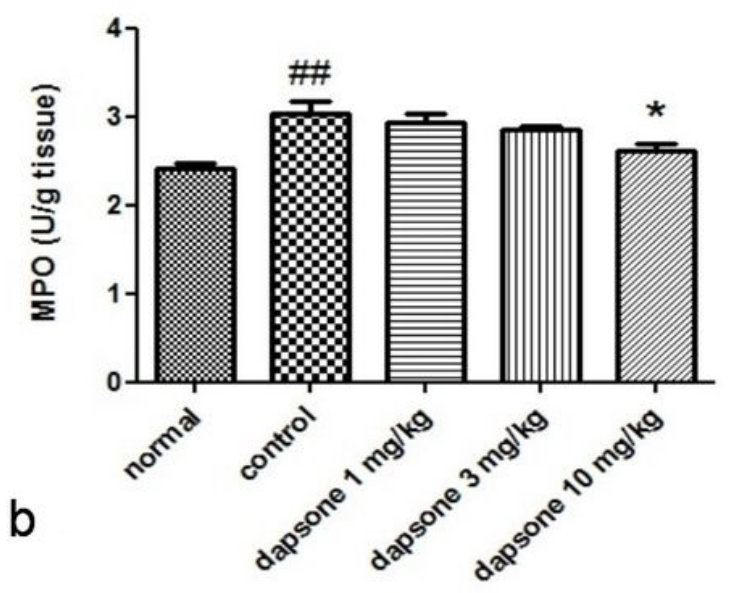

\section{Myeloperoxidase (indomethacin-induced ulcer)}

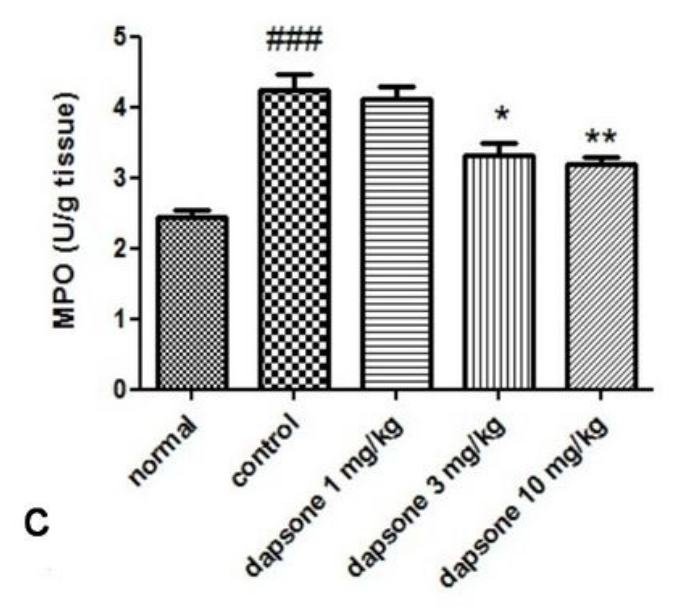

Figure 5

Tissue levels of MPO in ethanol-induced erosion group (a); stress-induced erosion group (b); indomethacin-induced erosion group (c). Results are expressed as mean $\pm S E M$; Number of animal in each group: 8, \#\#\#P<0.001, compared to normal group; $* P<0.05$, $* * P<0.01$, compared to control group 
a
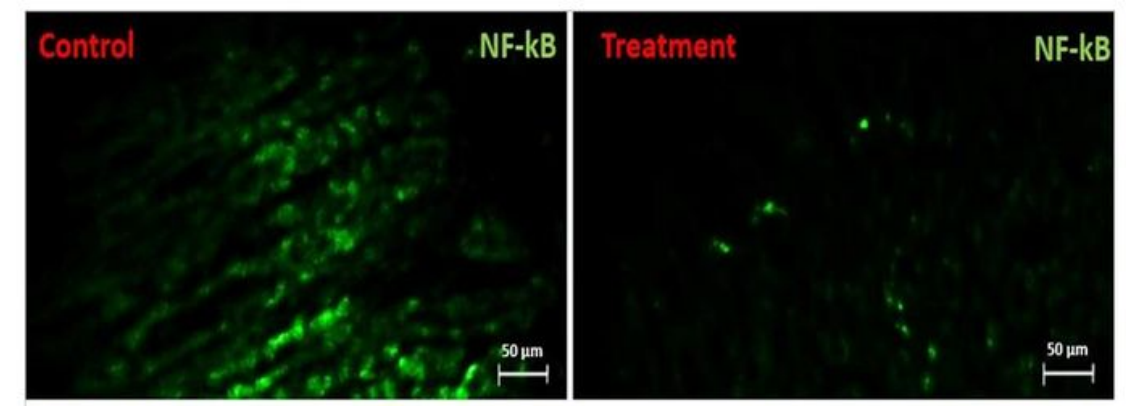

b
Expression of NF-KB (ethanol-induced ulcer)
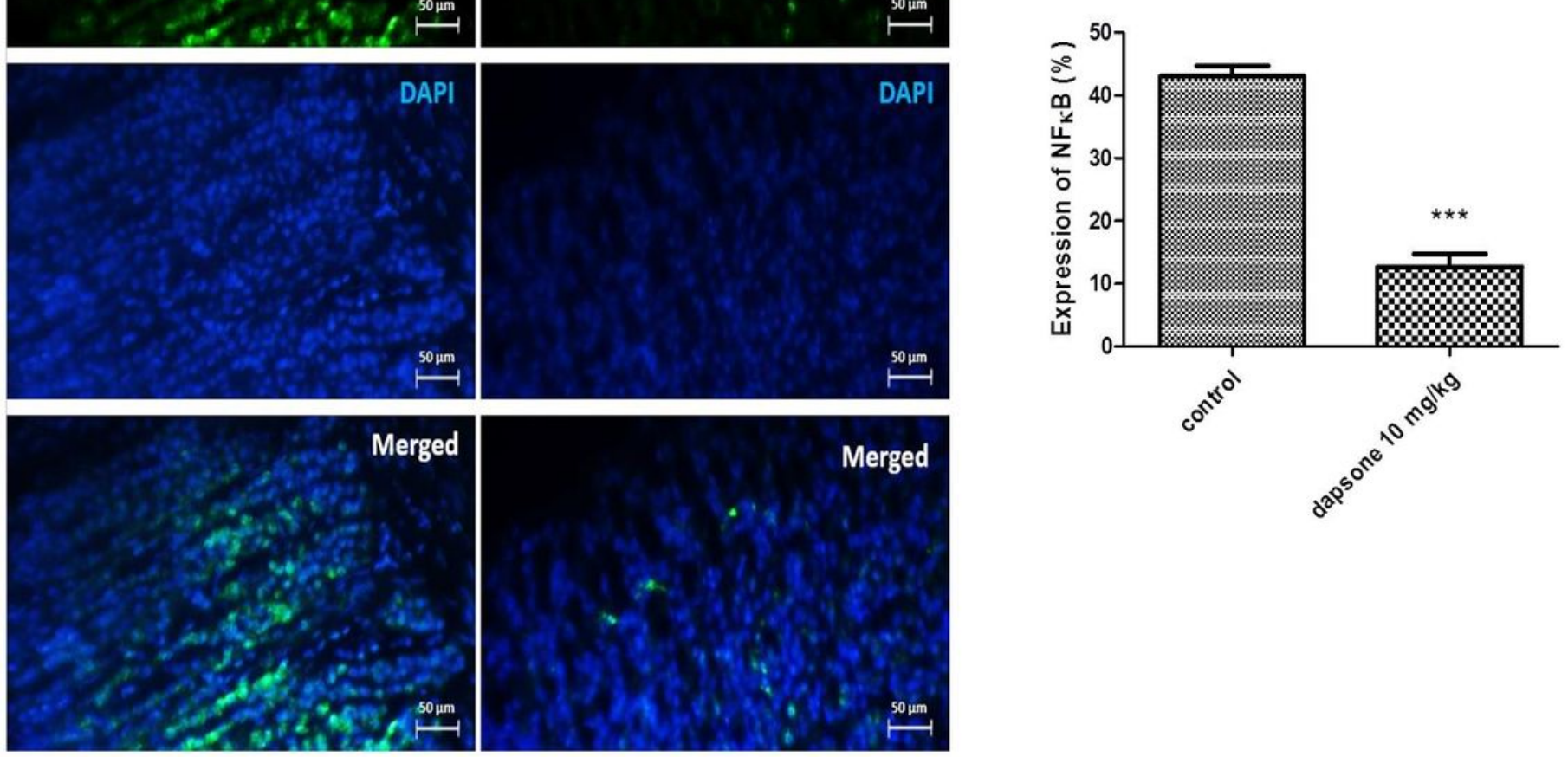

Figure 6

Immunohistochemical staining of NF-KB p65 expression in the gastric tissue of rats in ethanol-induced erosion model $(\times 40)$, stained with DAPI (blue), through immunofluorescence via an antibody bound to fluorescein isothiocyanate (FITC) (green) (a). Immunohistochemical analysis of gastric tissue sections for NF-KB expression in ethanol-induced ulcer model (b). Results are expressed as mean \pm SEM. Number of animals in each group: $8 .{ }^{* \star *} \mathrm{p}<0.001$ compare to control group 
a
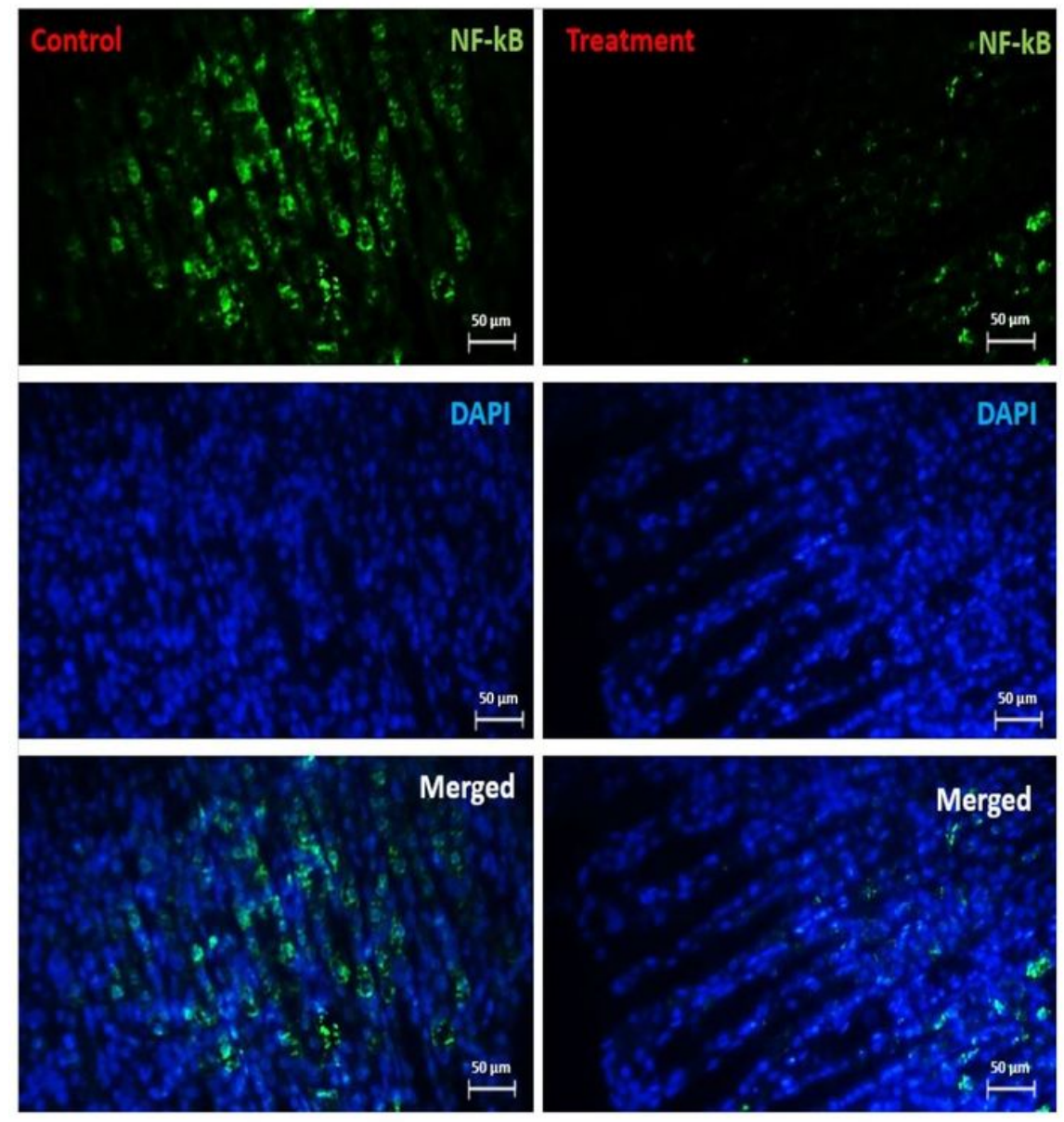

b

Expression of NF-kB (stress-induced ulcer)

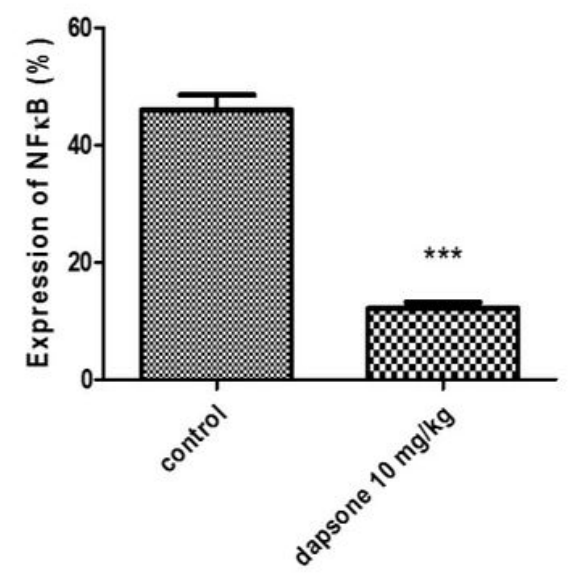

Figure 7

Immunohistochemical staining of NF-KB p65 expression in the gastric tissue of rats in stress-induced erosion model $(\times 40)$, stained with DAPI (blue), through immunofluorescence via an antibody bound to fluorescein isothiocyanate (FITC) (green) (a). Immunohistochemical analysis of gastric tissue sections for NF-KB expression in stress-induced erosion model (b). Results are expressed as mean \pm SEM. Number of animals in each group: 8 . ${ }^{\star \star} \mathrm{p}<0.001$ compare to control group 
a

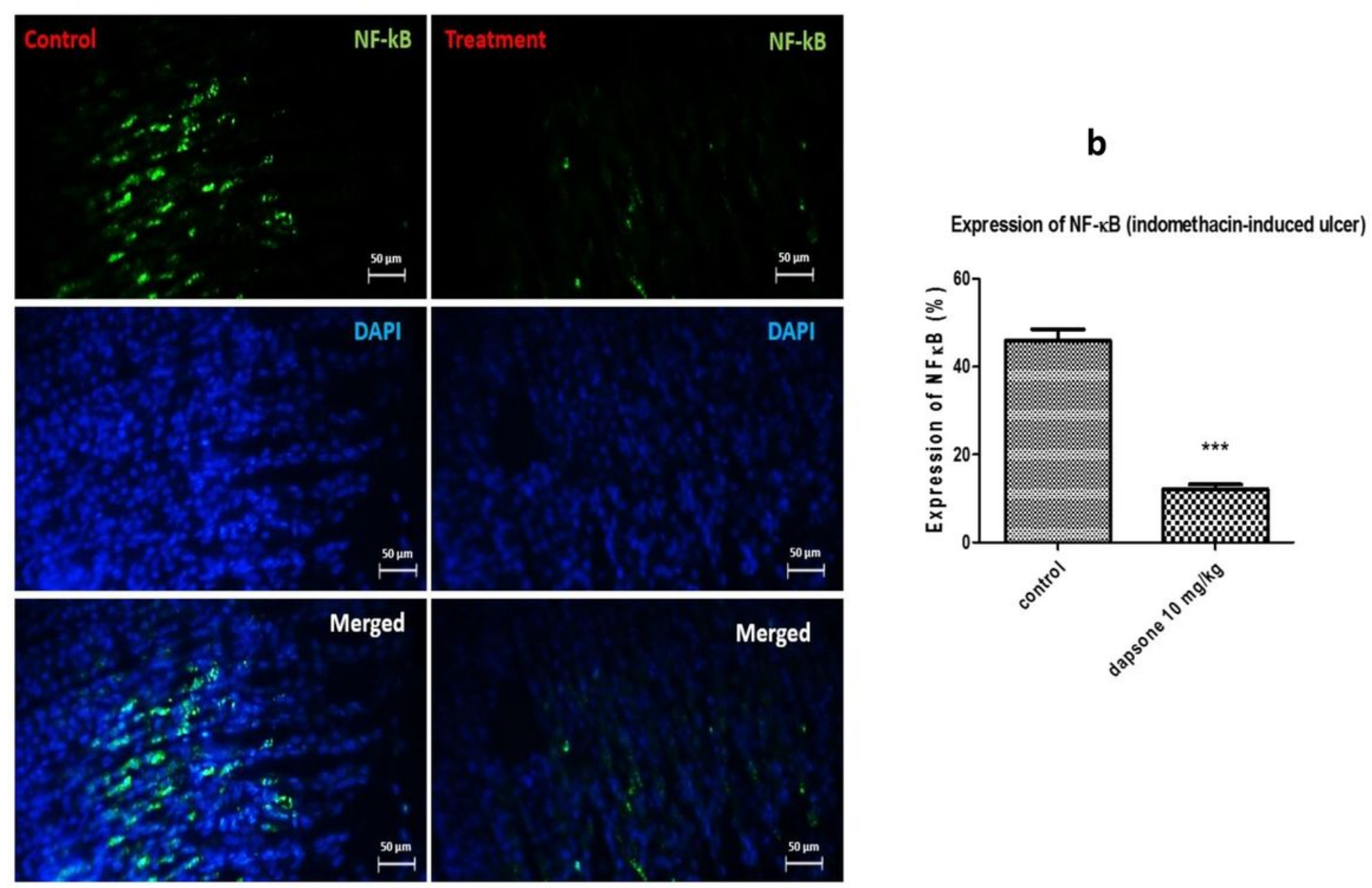

Figure 8

Immunohistochemical staining of NF-KB p65 expression in the gastric tissue of rats in indomethacininduced erosion model ( $\times 40)$, stained with DAPI (blue), through immunofluorescence via an antibody bound to fluorescein isothiocyanate (FITC) (green) (a). Immunohistochemical analysis of gastric tissue sections for NF-KB expression in indomethacin-induced erosion model (b). Results are expressed as mean $\pm S E M$. Number of animals in each group: 8 . ${ }^{\star \star *} p<0.001$ compare to control group 